\title{
A Cadaveric Report on a Giant Ureteric Stone Led Right Hydro Ureter and Severe Hydronephrosis
}

\author{
Suhani Sumalatha ${ }^{1}$, Sushma R Kotian ${ }^{1 *}$, Ashwija Shetty ${ }^{1}$, Rohini Punja ${ }^{1}$, \\ Deepak Nayak ${ }^{2}$, Punnose $K^{1}$
}

\section{OPEN ACCESS}

Citation: Suhani Sumalatha, Sushma R Kotian, Ashwija Shetty, Rohini Punja, Deepak Nayak, Punnose K. A Cadaveric Report on a Giant Ureteric Stone Led Right Hydro Ureter and Severe Hydronephrosis. Ethiop J Health Sci.2019;29(5):649.doi:http:// dx.doi.org/ 10.4314/ejhs.v29i5.16

Received: March 19, 2019

Accepted: July 1, 2019

Published: September 1, 2019

Copyright: (C) 2019 Suhan S., et al. This is an open access article distributed under the terms of the Creative Commons Attribution License, which permits unrestricted use, distribution, and reproduction in any medium, provided the original author and source are credited. Funding: Nil

Competing Interests: The authors declare that this manuscript was approved by all authors in its form and that no competing interest exists.

Affiliation and Correspondence: ${ }^{1}$ Department of Anatomy, Kasturba Medical College Manipal, Manipal Academy of Higher Education

${ }^{2}$ Department of Pathology, Kasturba Medical College Manipal, Manipal Academy of Higher Education

*Email: sushma.rk@manipal.edu

\section{ABSTRACT}

BACKGROUND: The ureter shows natural constrictions in its course, and these are the potential site for the impaction of the renal calculus. Giant ureteral stones are associated with insidious growth and late presentation, often leading to renal failure.

CASE PRESENTATION: In the present case, we observed a huge ureteric stone obstructing the right ureterovesical junction in a 58 year-old male cadaver. We also found hydroureter distal to the impaction of the calculus, renal damage and severe hydronephrosis on the right side. Histopathological analysis showed conditions of arterio-nephro-sclerosis and eroded ureter secondary to the calculus. Ureteric stones obstruction may result in hydroureter, hydronephrosis and progressive renal damage leading to irreversible renal function. The present case provides valuable information regarding the gross and histopathological alterations in ureteric calculi.

CONCLUSION: It further enables clinicians to be armed with the knowledge of preventive approaches to educate patients with previous calculi, or those who may develop in the future.

KEYWORDS: Hydronephrosis, Kidney,South Indian, Histopathological, Ureteric stone.

\section{CASE REPORT}

During routine anatomical dissection, we encountered a rare condition in the right kidney and ureter of a 58 year-old male cadaver. The renal pelvis and the ureter were grossly dilated without any visible external anatomical changes in the shape (Figure 1a). The right kidney measured about $12.5 \times 5.5 \mathrm{~cm}$ in length and breadth while the ureter was $20.5 \mathrm{~cm}$ long. The wall of the renal pelvis on the right side was thin when compared to the ureter, and its circumference measured $6.3 \mathrm{~cm}$ with the width of $1.2 \mathrm{~cm}$. The width and the circumference of the ureter along its course were not uniform; thus, its width and circumference were measured at three different pointsa) pelviureteric junction $6.5 \times 3.25 \mathrm{~cm}$, b) pelvic brim $2.15 \mathrm{~cm} \mathrm{X} 4.3 \mathrm{~cm}$, c) close to the bladder $5.3 \mathrm{cmX} 4.4 \mathrm{~cm}$. Dissection of the right ureter presented a huge ureteric stone measuring about $2 \mathrm{~cm}$ in length and $1.2 \mathrm{~cm}$ in breadth impeding the lumen at the ureterovesical junction. The ureteric stone was dark green with a rough granular surface and 
weighing about $3.569 \mathrm{~g}$ (Figure $1 \mathrm{~b}$ ). The right kidney on the sagittal section appeared hollow and showed dilated calyces and dilated renal pelvis. A clear demarcation between the cortex and medulla was lost with evident degeneration and cavitation of the renal pyramids (Figure 1c).
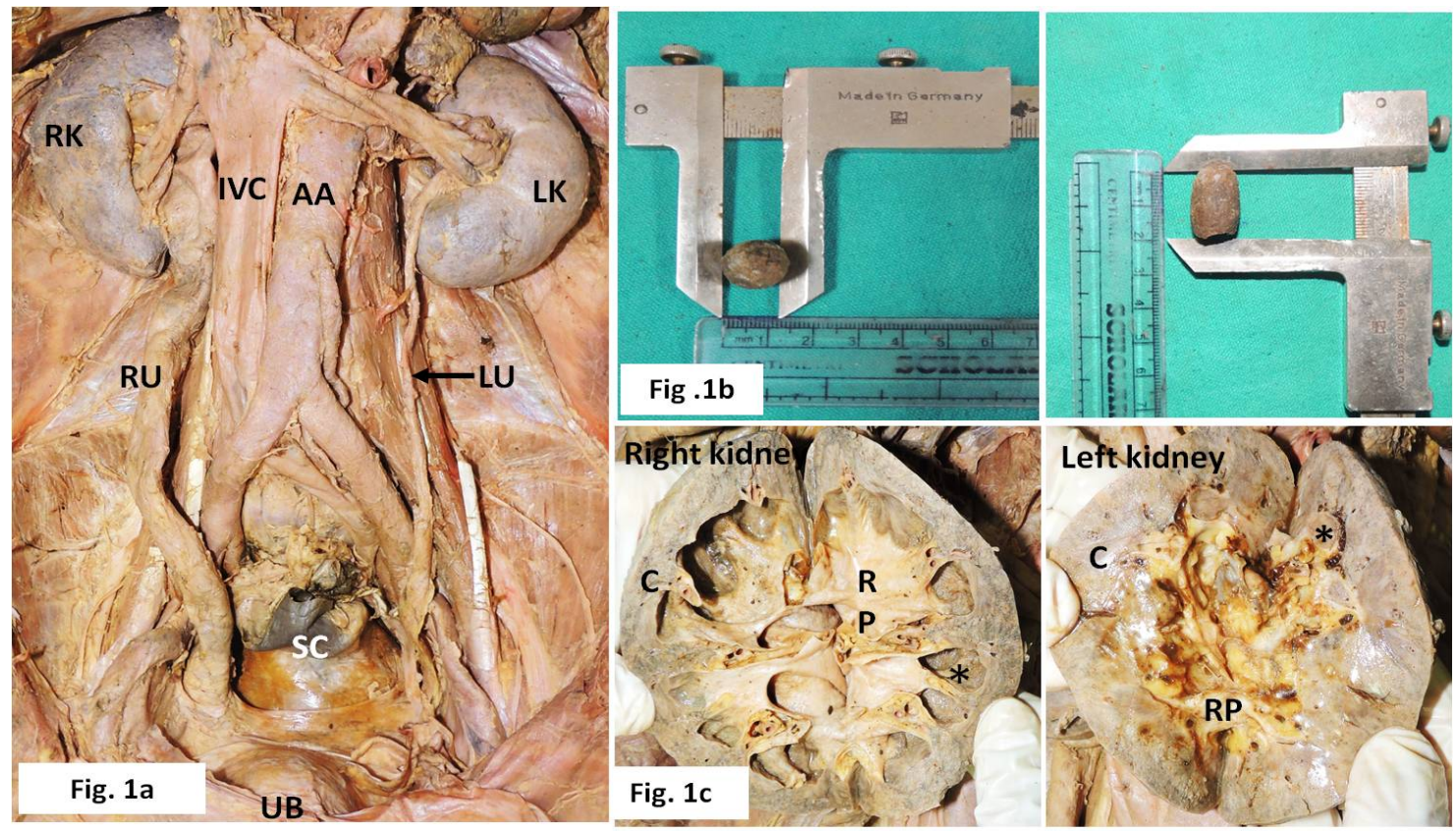

Figure1a: A severely dilated right ureter (RU); the right kidney (RK) however appearing normal externally: LK- left kidney; LU- left ureter; UB-Urinary Bladder, IVC-Inferior vena cava; AA-Abdominal aorta, SC-Sigmoid colon

Figure $1 \mathrm{~b}$ : The ureteric stone $(1.2 \mathrm{~cm} \times 2 \mathrm{~cm})$ lodged at the right ureterovesical junction

Figure 1c: Sagittal section of the right kidney showing a dilated right renal pelvis, cavitation of the renal pyramid and thin renal cortex and the left kidney showing normal morphology: C-Cortex; RP-Renal pelvis; *- renal pyramid
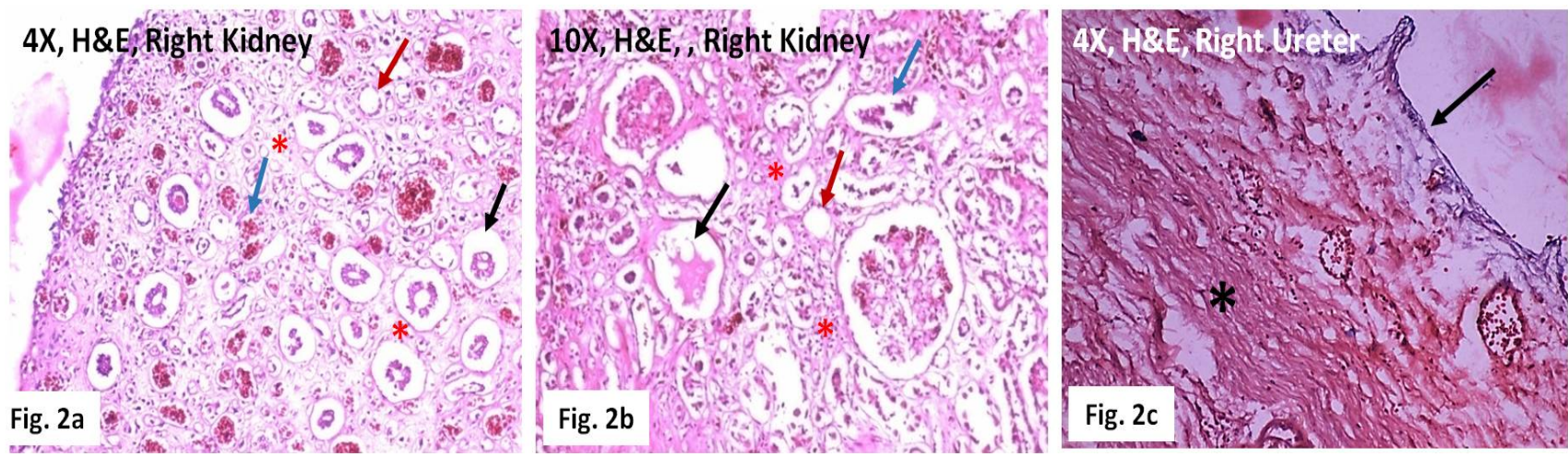

Figure 2: Histopathological observations made in the right kidney and ureter using $H \& E$ stain

Figures $2 \boldsymbol{a} \&$ 2b: Sclerosed glomeruli (black arrow), autolysis of tubular cells (red arrow) and capillary congestion (blue arrow) at $4 X$ and $10 X$ magnifications; cellular infiltration and the wider separations of the kidney tubules are also possibily indicating the signs of inflammation and fibrosis (Indicated by*)

Figure 2c: Eroded urothelium (indicated by black arrow) and de-arrangement of muscle layer (indicated by *) with hypertrophy secondary to calculus

DOI: http://dx.doi.org/10.4314/ejhs.v29i5.16 
Histopathological observations suggested ArterioNephro-Sclerosis of the kidney. The kidney exhibited sclerosed glomeruli, autolysis of tubular cells and capillary congestion. The Interstitial stroma showed minimal inflammatory changes (Figure 2a \& 2b).The ureter exhibited eroded urothelium and de-arrangement of muscle layer with hypertrophy secondary to calculus (Figure 2c).

The left kidney and ureter were found to be normal. The length and breadth of the kidney were $11.5 \times 4.5 \mathrm{~cm}$ while the ureter presented a total length of $18 \mathrm{~cm}$ on the left side. Also, the right and the left renal arteries and veins were observed to be of normal dimensions.

Ethical approval: The present study was conducted on a cadaver donated for the purpose of medical education and research. All procedures performed was in accordance with the ethical standards of the institutional and/or national research committee and with the 1964 Helsinki declaration and its later amendments/comparable ethical standards.

\section{DISCUSSION}

The incidence of urolithiasis is increasing globally. Studies in the western population revealed that urolithiasis is more common in males (124 per 1000) than in females (36 per $100,000)(3)$. The present case was also observed in a male cadaver and is similar to the case reported by Iravani et al. in 2014 (4). Ureteric or renal calculi lead to various degrees of complications like -Hydronephrosis, renal damage, urinary tract infection and urosepsis. The hydronephrosis results due to obstruction in the urinary system leading to dilation and swelling of the kidney. The incidence of ureteric/kidney stone is as high as 1 in 100 people. It usually effects unilaterally and can be treated by removal of the obstruction followed by the antibiotics for circumventing the infections (5). If the condition is untreated or mismanaged, it can result in permanent damage to the kidney and renal failure. This situation could be devastating in an individual with a single kidney. In the present case, the cadaver was donated, and no known clinical condition during living was documented.
Iravani et al. 2014 in their case described a large ureteric stone resulting in the complete obstruction of the left ureterovesical junction, leading to severe dilatation of the left ureter and renal pelvis with shrunken kidney. In the present study, similar observations were made on the right side. However, the right kidney was not shrunken. Further, histopathology of the right kidney presented with sclerosed glomeruli, autolysis of tubular cells and capillary congestion. The right ureter showed an eroded urothelium and dearrangement of the muscle layer with hypertrophy secondary to the calculus.

The present case provides valuable information regarding the gross and histopathological alterations in the conditions of ureteric calculi. It further enables the clinicians to be armed with the knowledge of preventive approaches to educate patients with previous calculi, or those that are prone to development.

\section{ACKNOWLEDGEMENT}

We would like to thank the head of our department for providing us the opportunity to use the details of variation in the cadaver for purpose of this study. 


\section{REFERENCES}

1. Standring S, Borley NR, Collins P, Crossman AR, Gatzoulis MA, Healy JC, Johnson D, Mahadevan V, Newell RL, Wigley CB. Gray's anatomy: the anatomical basis of clinical practice. 40th ed. Edinburgh, Elsevier, 2008:1242.

2. Park J, Siegel C, Moll M, Konnak J. Retrograde ureteral intussusception. J Urol 1994; 151:997-98.

3. Johnson CM, Wilson DM, O'Fallon WM, Malek RS, Kurland LT. Renal stone epidemiology: A 25-year study in Rochester, Minnesota. Kidney Int1979; 16:624-31.

4. Iravani O, Tay EW, Bay $\mathrm{BH}, \mathrm{Ng} \mathrm{YK}$. Unilateral ureteric stone associated with gross hydronephrosis and kidney shrinkage: a cadaveric report. Anat Cell Biol 2014; 47:26770.

5. Ascenti G, Siragusa C, Racchiusa S, et al. Stone-targeted dual-energy CT: a new diagnostic approach to urinary calculosis. AJR Am J Roentgenol 2010; 195:953-58. 